УдК 336.7

\author{
НАУМЕНКО СВЕТААНА МИХАЙЛОВНА \\ к.э.н., доцент Северо-Кавказский филиал Белгородского \\ государственного технологического университета им. В. Г. Шухова, \\ e-mail: naumenkosm2012@mail.ru \\ ШЕВЦОВА ОЛЬГА НИКОЛАЕВНА \\ к.э.н., доцент Северо-Кавказский филиал Белгородского \\ государственного технологического университета им. В. Г. Шухова, \\ e-mail: olichkanik888@mail.ru
}

\title{
РАЗРАБОТКА ПОКАЗАТЕАЕЙ УРОВНЯ ФИНАНСОВОЙ СОСТАВАЯЮЩЕЙ ЭКОНОМИЧЕСКОЙ БЕЗОПАСНОСТИ БАНКА И СТРАТЕГИЙ ПО ЕЁ СОВЕРШЕНСТВОВАНИЮ
}

\begin{abstract}
Аннотауия. В современных условиях развитие экономической и финансовой сферы сопряжено с применением стратегического планирования. Стратегическое планирование помогает в условиях нестабильности среды прогнозировать риски и избегать состояния кризиса. Грамотное определение стратегической направленности развития позволяет обеспечить экономическую безопасность предприятию. Уровень экономической безопасности ориентирован на расчет спеииальных индикаторов (показателей), способных дать оиенку по критерию, путем выделения слабых и сильных зон, угроз и возможностей. $B$ статье анализируемая методика применена к деятельности коммерческого банка ОАО «Ставропольпромстройбанк», произведен расчет показателей. По итогам проведенной оиенки предложены направления применения стратегий развития финансового учреждения, позволяющие укрепить свои конкурентные преимущества и стабилизировать экономическую безопасность. Таким образом, в статье доказывается целесообразность применения стратегического планирования в деятельности банковских учреждений и хозяйствующих субъектов в целом.
\end{abstract}

Ключевые слова: экономическая безопасность, стратегическое планирование, риск, финансовая политика, банковская система.

NAUMENKO SVETLANA MIKHAILOVNA

Ph. D., associate Professor, North Caucasus branch of Belgorod state University

V. G. Shukhov state technological University, e-mail:naumenkosm2012@mail.ru

SHEVTSOVA OLGA NIKOLAEVNA

Ph. D., associate Professor, North Caucasus branch of Belgorod state University V. G. Shukhov state technological University, e-mail: olichkanik888@mail.ru

\section{DEVELOPMENT OF INDICATORS OF THE LEVEL OF THE FINANCIAL COMPONENT BANK'S ECONOMIC SECURITY AND STRATEGIES HOW TO IMPROVE IT}

\begin{abstract}
In modern conditions, the development of the economic and financial sphere involves the use of strategic planning. Strategic planning helps to predict risks and avoid a state of crisis in an unstable environment. Competent determination of the strategic direction of development allows to ensure economic security of the enterprise. The level of economic security is focused on the calculation of special indicators (indicators) that can give an assessment by the criterion, by identifying weak and strong zones, threats and opportunities. In the article, the analyzed method is
\end{abstract}


НАУМЕНКО С.М., ШЕВЦОВА О.Н.

РАЗРАБОТКА ПОКАЗАТЕЛЕЙ УРОВНЯ ФИНАНСОВОЙ СОСТАВЛЯЮЩЕЙ ЭКОНОМИЧЕСКОЙ БЕЗОПАСНОСТИ БАНКА И СТРАТЕГИЙ ПО ЕЁ СОВЕРШЕНСТВОВАНИЮ

applied to the activities of the commercial Bank of JSC "Stavropolpromstroybank", the calculation of indicators is made. Based on the results of the assessment, the directions of application of financial institution development strategies that allow to strengthen their competitive advantages and stabilize economic security are proposed. Thus, the article proves the feasibility of applying strategic planning in the activities of banking institutions and business entities in General.

Keywords: economic security, strategic planning, risk, financial policy, banking system.

Введение. В настоящее время роль стратегического планирования резко возрастает во всех сферах деятельности. Это обусловлено процессами глобализации в мире, возрастанием масштабов и сложности задач, решаемых органами управления различных уровней и структур.

Обеспечить экономическую безопасность предприятия, его независимость и недопущение скатывания в зону критического риска можно в том случае, когда четко определены главные стратегические направления обеспечения безопасности бизнеса. Необходимо построить логическую схему своевременного обнаружения и ликвидации возможных опасностей и угроз, уменьшения последствий хозяйственного риска. Для того чтобы создать надежную систему безопасности предприятия, надо провести комплекс подготовительных мероприятий. От этой работы во многом зависит, какие решения необходимо принять в этой области, каким образом сформировать органы безопасности, какие будут выделены финансовые, материальные и человеческие ресурсы, а в итоге - эффективность обеспечения безопасности бизнеса.

Многие факторы могут привести кредитную организацию к кризису. Прежде всего, это отсутствие системы предупреждения и профилактики развития подобных проявлений и подход к ведению хозяйственной деятельности по принципу: «Если сейчас проблемы нет и она не мешает, то не нужно думать, что она появится завтра».

Понятно, что любую проблему гораздо легче предотвратить, нежели решать ее по факту возникновения. Надо четко и объективно понимать:

- в чем компания сильна и где ее слабые места;

- насколько профессиональны и добросовестны люди, от которых зависит принятие серьезных управленческих решений;

- представлять объем и реальность внешних и внутренних угроз.

Методы исследования. Для всех имеющихся угроз, сил, возможностей и слабостей по финансовой составляющей экономической безопасности разработаны показатели оценки уровня экономической безопасности Saf (от слова Safety - безопасность):

$$
\text { Saf }(\text { Now })=\mathrm{S} 1+\mathrm{S} 2+\mathrm{Sn}+\mathrm{W} 1+\mathrm{W} 2+\mathrm{Wn} \text {, }
$$

где Saf (Now) -текущая безопасность банка.

$\mathrm{Sn}$ - сильная сторона банка. Каждой сильной стороне присваивается значение от 0 до 1 в зависимости от того, как она компенсирует определенную слабость.

$\mathrm{Wn}$ - слабая сторона банка. Каждой слабой стороне присваивается значение минус 1.

$$
\mathrm{Saf}(\text { Forcast })=\mathrm{S} 1+\mathrm{S} 2+\mathrm{Sn}+\mathrm{Op} 1+\mathrm{Op} 2+\mathrm{Opn}+\mathrm{Tr} 1+\mathrm{Tr} 2+\operatorname{Trn},
$$

где Saf (Forcast) - прогнозная безопасность банка.

Opn - определенная возможность банка в разрешение угрозы. Присваивается значение от 0 до 1.

$\operatorname{Tr}$ - угроза банка. Каждому показателю угрозы присваивается значение минус 1.

$$
\mathrm{Saf}(\mathrm{Full})=\sum \mathrm{Op}+\sum \mathrm{S}+\sum \mathrm{W}+\sum \mathrm{Tr},
$$

где Saf (Full) - полная безопасность банка.

В расчетах показателям W и $\operatorname{Tr}$ будет всегда присваиваться значение (-1), и их всегда будет столько, сколько есть пунктов угроз и слабостей.

Показатели же сил и возможностей могут использоваться несколько раз в зависимости от 
того, сколько угроз и слабостей они могут компенсировать.

Если $\mathrm{Saf}=0$, то безопасность полная (все угрозы и слабости скомпенсированы).

Если $\mathrm{Saf}<0$, то безопасность низкая (существуют неразрешенные угрозы).

Если $\mathrm{Saf}>0$, то безопасность высокая (высокий уровень безопасности, но возможны чрезмерные излишние затраты на нее).

Результаты. Рассчитаем текущую, прогнозную и полную безопасность ОАО «Ставропольпромстройбанк».

Для этого соотнесем отрицательные и положительные факторы, влияющие на безопасность банка, данные представим в табл. [31].

\section{Соотношение составляющих финансовой безопасности ПАО} «Ставропольпромстройбанк»*

\begin{tabular}{|c|c|c|c|c|c|c|c|c|c|c|c|c|c|c|c|c|}
\hline & \multirow{3}{*}{$* *$} & \multicolumn{13}{|c|}{ Положительные факторы } \\
\hline & & & & \multicolumn{6}{|c|}{ Сильные стороны } & \multicolumn{6}{|c|}{ Возможности } & \multirow{2}{*}{$* * *$} \\
\hline & & & & S1 & S2 & S3 & S4 & S5 & S6 & $\mathrm{O} 1$ & $\mathrm{O} 2$ & $\mathrm{O} 3$ & $\mathrm{O} 4$ & O5 & O6 & \\
\hline \multirow{12}{*}{ 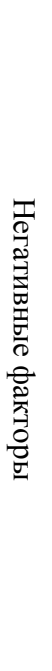 } & \multirow{5}{*}{ 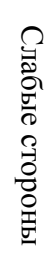 } & W1 & -1 & - & 1 & - & $-0,5$ & $-0,5$ & - & 1 & 1 & 1 & 1 & 0,5 & 0,5 & 5 \\
\hline & & W2 & -1 & - & 0,5 & - & $-0,5$ & -1 & - & 1 & 1 & 1 & 0,5 & - & 0,5 & 3,5 \\
\hline & & W3 & -1 & - & 0,5 & - & $-0,5$ & 0,5 & - & 0,5 & - & 0,5 & 1 & 1 & 0,5 & 4,5 \\
\hline & & W4 & -1 & 1 & 0,5 & 0,5 & 0,5 & $-0,5$ & - & 1 & 0,5 & 1 & 0,5 & -1 & 0,5 & 5 \\
\hline & & W5 & -1 & 0,5 & 0,5 & 0,5 & 0,5 & 0,5 & - & - & - & - & - & - & 0,5 & 3 \\
\hline & \multirow{6}{*}{ 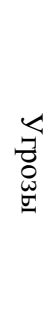 } & $\mathrm{T} 1$ & -1 & 1 & 1 & 1 & 0,5 & 0,5 & 0,5 & 0,5 & 0,5 & 0,5 & 0,5 & - & 0,5 & 7 \\
\hline & & $\mathrm{T} 2$ & -1 & 1 & 1 & - & 1 & 1 & 0,5 & - & - & - & - & - & 1 & 5,5 \\
\hline & & $\mathrm{T} 3$ & -1 & 1 & 1 & - & - & 1 & - & - & - & - & - & - & 1 & 4 \\
\hline & & $\mathrm{T} 4$ & -1 & - & 1 & - & - & 1 & 1 & - & - & - & - & - & 1 & 4 \\
\hline & & T5 & -1 & - & - & 1 & - & - & - & - & - & - & - & - & 1 & 2 \\
\hline & & T6 & -1 & - & - & - & - & - & 1 & - & - & - & - & - & 1 & 2 \\
\hline & \multicolumn{3}{|c|}{$* * * *$} & 4,5 & 6,5 & 2 & 3 & 3 & 3 & 4 & 3 & 4 & 3,5 & 0,5 & 8 & \\
\hline
\end{tabular}

*Источник: составлено авторами.

** - балл значения негативного фактора.

*** - балл нейтрализации негативного фактора.

****_ балл значимости положительного фактора.

В процессе соотношения положительных и отрицательных факторов, влияющих на безопасность банка, происходит формирование стратегий повышения её эффективности.

Параметр S1. ПАО «Ставропольпромстройбанк» имеет огромный опыт по массовому обслуживанию клиентов.

В будущем этот опыт будет иметь сильное влияние на деятельность банка. Однако в перспективе крупные банки-конкуренты также смогут качественно и эффективно обслуживать клиентов, что несколько снизит значение данного параметра, что потребует поиска новых конкурентных преимуществ.

Параметр S2. С развитием банковского рынка в РФ значимость высоких профессиональных навыков возрастает, это относится и к экономической безопасности. Банк тщательно подбирает сотрудников, квалификация которых не вызывает сомнений. В коллективе царит дружественная рабочая атмосфера. Текучка кадров в банке отсутствует.

Параметр S3. ПАО «Ставропольпромстройбанк» имеет репутацию надежного партнера. Его услуги предпочитают многие физические лица и организации: кредитные ресурсы банка помогают в настоящее время модернизироваться концерну ОАО НПК «ЭСКОМ».

Параметр S4. В течение 2019 г. Банк предоставлял продукты, отдавая предпочтение краткосрочному кредитованию. В сложившихся условиях кредитная политика Банка была направлена на умеренно-взвешенное увеличение объемов при улучшении качества кредитного порт- 
НАУМЕНКО C.M., ШЕВЦОВА О.Н.

РАЗРАБОТКА ПОКАЗАТЕЛЕЙ УРОВНЯ ФИНАНСОВОЙ СОСТАВЛЯЮЩЕЙ ЭКОНОМИЧЕСКОЙ БЕЗОПАСНОСТИ БАНКА И СТРАТЕГИЙ ПО ЕЁ СОВЕРШЕНСТВОВАНИЮ

феля.

Параметр S5. Хоть излишняя финансовая устойчивость и несколько негативно влияет на деятельность, так как увеличивает затраты чрезмерными резервами, но у предприятия отсутствует риск банкротства. Поэтому, по мнению авторов, это является сильной стороной предприятия.

Параметр S6. Банк использует новейшие средства защиты информации, осуществляет мониторинг за появляющимися криминальными факторами и сотрудничает с лучшими охранными предприятиями.

Параметр W1. Неэффективная процентная политика банка наблюдается вследствие снижения процентных доходов и увеличения процентных расходов. Процентные доходы уменьшились за счет значительного уменьшения ссуд, предоставленных клиентам (некредитным организациям), а процентные расходы увеличились за счет увеличения привлеченных средств некредитных организаций.

Параметр W2. Недостаточно эффективная работа активов банка наблюдается вследствие снижения объема прибыли на каждый рубль активов.

Параметp W3. Слишком высок коэффициент срочных обязательств. Деятельность банка меньше направлена на минимизацию затрат, так как срочные обязательства являются более дорогими средствами привлечения, чем обязательства до востребования.

Параметр W4. За последний год произошло значительное снижение объемов кредитного портфеля. Так как экономика еще находится в посткризисном состоянии, банк сдерживает развитие в пользу устойчивости и выдает меньше кредитов.

Параметр W5. Нехватка достоверных источников информации о клиентах, особенно кредиторах. Эта слабая сторона характерна для всего банковского сектора России. За границей эта информация общедоступна, и банки свободно ею пользуются, в нашей стране - она в закрытом доступе. Невозможно на $100 \%$ определить правдивость заемщика, поэтому фальсификация документов и данных - не редкость.

Параметр O1. Банк имеет достаточно запаса устойчивости для увеличения кредитного портфеля, привлечения новых клиентов.

Параметр О2. Развивающийся рынок ценных бумаг будет иметь особое значение для деятельности банка в перспективе. Являясь активным участником рынка ценных бумаг на ведущих торговых площадках страны, банк постоянно увеличивает объем капиталовложений в различные инструменты российского рынка ценных бумаг.

Параметр О3. В своей деятельности Банк практически не использует такой доходный вид вложения средств, как межбанковский кредит.

Параметр O4. Минимизация затрат является важнейшим элементом повышения функционирования деятельности любого предприятия. Для «Ставропольпромстройбанка» особо актуален вопрос минимизации процентных и операционных, так как они сильно повлияли на отрицательную динамику прибыли.

Параметр О5. Слишком высок коэффициент срочных обязательств.

Деятельность банка меньше направлена на минимизацию затрат, так как срочные обязательства являются более дорогими средствами привлечения, чем обязательства до востребования.

Параметр О6. Банк имеет возможность и постоянно совершенствует систему экономической безопасности, проводит мониторинг, анализ и внедрение новых мероприятий по предотвращению новых угроз.

Параметр T1. С развитием рынка банковских услуг неумолимо растет и конкуренция на нем. Банковская система Ставропольского края представлена Сберегательным банком, $11 \mathrm{ca-}$ мостоятельными банками. В регионе сложился особый тип конкуренции - олигополии доминирования. Однако постепенно преимущество переходит к хорошо капитализированным банкам, которые способны быстро применять новейшие технологии, оперативно развивать продуктовый ряд, создавать обширную сеть филиалов, дополнительных офисов.

Параметр Т2. Банковская деятельность сопровождается множеством финансовых рисков, и недоучет каждого из них губителен и может привести к банкротству.

Деятельность банка достаточно обширна и имеет очень много аспектов, которые необходи- 
мо учитывать. Если в стратегическом планировании пропустить хоть один из важных факторов, то это может привести к серьезным негативным последствиям и убыткам.

Параметр Т3. Непредвиденные обстоятельства должны всегда учитываться в банковской деятельности - их необходимо предусмотреть и выделить необходимые резервные средства для их предотвращения.

Параметр T4. В современным мире криминальный фактор играет значительную роль преступников становится все больше, и они становятся умнее, изощреннее. Клиенты банков страдают от действий мошенников, и Банк должен делать все возможное для пресечения этого.

Параметр T5. Репутация всегда имеет важную роль в деятельности предприятия. В банковском секторе потеря репутации означает потерю клиентов, ведет к банкротству и кризисам.

Параметр Т6. Утечка конфиденциальной информации, попадание её в руки конкурентов может сильно навредить финансовой стороне банковской деятельности.

Проектирование стратегий по разработанной ранее SWOT-матрице осуществляется следующим образом. На основе ранее созданной SWOT-матрицы проектируются стратегии четырех типов:

- Стратегии вида $\mathrm{SO}$ - силы-возможности.

- Стратегии вида ST - силы-угрозы.

- Стратегии вида WO - слабости-возможности.

- Стратегии вида WT - слабости-угрозы.

В работе были сформированы стратегии типа WO и ST. В стратегиях были отражены факторы, наиболее значимо влияющие на показатель.

Стратегия $\mathrm{W1}=\mathrm{O1}+\mathrm{O} 2+\mathrm{O3}+\mathrm{O} 4$

Неэффективная процентная политика Банка возникла в связи с увеличением процентных расходов - увеличилось количество депозитов и уменьшением процентных доходов - выдается меньше кредитов. Следовательно, повысить процентные доходы можно, увеличивая объем кредитного портфеля, привлекая новых клиентов и выдавая межбанковский кредит, а также увеличивая количество операций на рынке ценных бумаг.

Уменьшение расходов, особенно процентных, поможет сделать процентную политику эффективной. Сокращение количества срочных обязательств и постоянный мониторинг системы экономической безопасности косвенно повлияют на повышение эффективности процентной политики.

Высокая квалификация сотрудников позволит Банку вовремя исправить неэффективную процентную политику и не допустить её ухудшения.

Чрезмерная финансовая устойчивость и умеренная кредитная политика негативно сказываются на процентной политике, оказывая сдерживающее воздействие, заключающееся в накоплении денежных средств, которые могли бы быть инвестированы.

\section{Стратегия W2 $=01+02+03$}

Недостаточно эффективную работу активов, заключающуюся в большом количестве неработающих активов, которые остаются в резерве в связи с чрезмерной финансовой устойчивостью и умеренной кредитной политикой, можно исправить, вложив излишние резервные средства в ценные бумаги либо в кредиты физических и юридических лиц, а также межбанковский кредит, так как он является не только доходным средством вложения активов, но и еще очень надежным.

Сокращение расходов и совершенствование системы экономической безопасности косвенно улучшат работу активов.

Стратегия W3 $=04+05$

У Банка слишком высок коэффициент срочных обязательств, количество которых следует уменьшить в пользу обязательств до востребования.

Стратегия W4= O1+O3

Снижение объемов кредитного портфеля можно компенсировать, используя широкие возможности по привлечению новых клиентов, межбанковского кредита.

Сокращение количества срочных обязательств может привести к тому, что у Банка не окажется возможности привлечения долгосрочных кредитов, так как обязательства до востребо- 
НАУМЕНКО С.М., ШЕВЦОВА О.Н.

РАЗРАБОТКА ПОКАЗАТЕЛЕЙ УРОВНЯ ФИНАНСОВОЙ СОСТАВЛЯЮЩЕЙ ЭКОНОМИЧЕСКОЙ БЕЗОПАСНОСТИ БАНКА И СТРАТЕГИЙ ПО ЕЁ СОВЕРШЕНСТВОВАНИЮ

вания хоть и дорогой источник дохода - но надежный и долгосрочный.

Стратегия W5=06

Такой отрицательный фактор, как нехватка достоверных источников, открытости информации о клиентах не может быть полностью скомпенсирован усилиями и возможностями Банка. Этот фактор существует из-за несовершенства российского законодательства, вследствие чего Банк не может самостоятельно справиться с этой проблемой, которая должна быть решена на государственном уровне. Банк лишь может постоянно совершенствовать систему безопасности и интенсивнее изучать уже имеющиеся источники. Также справиться с этой ситуацией Банку поможет большой опыт, высококвалифицированный персонал и умеренная кредитная политика - при любых сомнениях и нехватке точных достоверных источников лучше отказать клиенту, чем подвергнуть предприятие излишнему риску.

Стратегия $\mathrm{T} 1=\mathrm{S} 1+\mathrm{S} 2+\mathrm{S3}$

Банк занимает устойчивую позицию в отрасли и имеет обширную клиентскую базу, высокую репутацию и отличных работников, что не позволит ему потерять конкурентные преимущества.

Стратегия T2=S1+S2+S4+S5

Недоучет финансовых рисков, неэффективное финансовое планирование могут быть губительны для компании, но наличие высококвалифицированного персонала, большого опыта и ведение банком осторожной кредитной политики обеспечат защиту от ошибок. Хотя в экстренной ситуации имеется достаточный запас резервов на их предотвращение.

Стратегия T3=S1+S2+S5

В случае наступления кризиса, стихийных бедствий и любых других непредвиденных внешних факторов имеются достаточные ресурсы для немедленной компенсации их последствий. Широкий опыт в бизнесе и наличие квалифицированного персонала позволят Банку быстро ориентироваться даже в экстренных ситуация. Постоянный мониторинг системы безопасности, повышение её стратегического уровня позволят предугадать и предусмотреть любые неприятности.

\section{Стратегия T4=S2+S5+S6}

Угроза криминального фактора компенсируется путем наличия и постоянного обновления современных систем защиты, наличием подготовленного к криминальным ситуациям персонала, а также непрерывным совершенствованием системы экономической безопасности. Наличие резервов и участие в системе страхования поможет справиться с негативными последствиями.

\section{Стратегия T5=S3}

Подрыв репутации Банка, любое распространение негативных слухов будет нейтрализовано высокой деловой репутацией и доверием клиентов банка.

\section{Стратегия T6=S6}

Совершенствование системы безопасности, её мониторинг и постоянное развитие и обновление систем защиты позволит избежать утечки важной конфиденциальной информацией и сохранить банковскую тайну.

Сопоставляя положительные и негативные факторы, мы присваивали значение (-1) всем негативным факторам; значение 1 - всем положительным факторам, прямо влияющим и компенсирующим негативные факторы, и значение 0,5 - положительным факторам, косвенно влияющим на негативные факторы.

Исходя из данных табл., проведем расчет показателей экономической безопасности ОАО «Ставропольпромстройбанк».

Saf $\quad(\mathbf{N o w})=\quad \mathbf{S 1}+\mathbf{S} 2+\mathbf{S n}+\mathbf{W} 1+\mathbf{W} 2+\mathbf{W n}=(-1+1-0,5-0,5)+(-1+0,5-1)+(-1+0,5--0,5+0,5)+(-$ $1+1+0,5+0,5+0,5)+(-1+0,5+0,5+0,5+0,5+0,5)=(-1)+(-1,5)+(-0,5)+1,5+1,5=0$.

Текущая безопасность Банка полная, так как все слабые стороны скомпенсированы сильными $(\mathrm{Saf}(\mathrm{Now})=0)$. То есть слабости Банка, конечно, имеют негативное влияние, но пока сильные стороны его нейтрализуют.

Saf $($ Forcast $)=\mathbf{S 1}+\mathbf{S} 2+\mathbf{S n}+\mathbf{O p} 1+\mathbf{O p 2}+\mathbf{O p n}+\mathbf{T r} 1+\operatorname{Tr} 2+\operatorname{Trn}=7+5,5+4+4+2+2--6=18,5$.

Таким образом, прогнозная безопасность Банка - высокая. Иными словами, каждая угроза компенсируется сильной стороной или возможностью Банка (Saf (Forcast) $>0$ ). То есть суще- 
ствует несколько вариантов нейтрализации возможные угроз.

Теперь рассчитаем полную безопасность Банка:

Saf $(\mathbf{F u l l})=\sum \mathbf{O p}+\sum \mathbf{S}+\sum \mathbf{W}+\sum \mathbf{T r}=5+3,5+4,5+5+3+7+5,5+4+4+2+2-11=34,5$.

Полная безопасность Банка - высокая ((Saf (Full) $>0))$. Это говорит о том, что Банк стабильно развивается и имеет множество возможностей для предотвращения угроз и нейтрализации слабостей.

Выводы. Подводя итог, можно сказать, что финансовая безопасность «Ставропольпромстройбанка» находится на достаточно высоком уровне. Хотя имеются слабости, негативно сказывающиеся на динамике развития Банка, но существует достаточно возможностей их нейтрализовать. Сильные стороны Банка позволяют предотвратить угрозы, которых достаточно в современной нестабильной рыночной среде.

Стратегическое планирование в самом общем виде - это, прежде всего, наука, которая способствует достижению поставленных целей с более высокой эффективностью при минимальных затратах.

Если руководство не считает нужным уделять должного внимания стратегическому планированию - оно, в конечном итоге, обрекает свое предприятие на неизбежное отставание от конкурентов. И наоборот, правильно выбранная стратегия дает существенные преимущества в развитии организации и преодолении кризисов.

Лuтература

1. Федеральный закон о банках и банковской деятельности от 02.12.1990 2. №395-1 Ф3 [ред. от 29.09.2011 2.].

2. Стратегия национальной безопасности Российской Федераџии до 2020 г. Утв. Указом президента РФ от 12 мая 2009 г. № 537.

3. Березина, М. П. Межбанковские расчеты : анализ практики / М.П. Березина, Ю.С. Крупнов. - М. : Деньги и Кредит, 2010.

4. Богомолов, В. А. Экономическая безопасность : учеб. пособие для студентов вузов, обучающихся по специальностям экономики и управления. - 2-е изд., перераб. и доп. - М. : ЮНИТИ-ДАНА, 2009.

5. Букато, В. И. Банки и банковские операции в России : учебник / В.И. Букато, Ю.И. Львов. - М. : Финансы и статистика, 2009.

6. Гамза, В. А. Ткачук, И. Б. Безопасность коммерческого банка : организаџионно-правовые и криминалистические проблемы : монография. - М. : Изд-ль Шумилова И.И., 2009.

7. Молчанов, А. В. Банковская система России : Настольная книга банкира ; ред. кол. Грязнова А.Г. и др. - М. : ДеКА, 2009.

8. Усоскин, В. М. Современный коммерческий банк : управление и операчии. 2010.

9. Окатьев, К. В. Научно-практическая работа на тему: «Экономико-организаџионные проблемы обеспечения безопасности деятельности коммерческих банков и пути развития и функционирования систем безопасности». - М., 2009.

10. Василенко, А. И. Вопросы экономической безопасности Российской Федерации // В мире науки. 2009. № 3. C. 21-23.

11. Власенко, М. Н. Информачионно-аналитическое обеспечение принятия управленческих решений значимый фактор повышения экономической безопасности хозяйствующих субъектов в условиях развития рыночной системы хозяйствования / М.Н.Власенко, Н.В. Унижаев // Нач. Интересь : приоритетыл и безопасность. 2010. № 33. С. 59-69.

12. Гордиенко, Д. В. Перспективы повышения уровня экономической безопасности России // Наи. Интересы : приоритеты и безопасность. 2010. № 15. С.33-4.

13. Жилкина, Ю. В. Подходы к обеспечению экономической безопасности // Наи. Интересы : приоритеты и безопасность. 2010. № 22. С. 62-70.

14. Канаев, А. В. Стратегические направления повышения экономической безопасности начиональной банковской системы [Текст] / А. В. Канаев // Финансы и кредит. 2008. № 20. С. 8-16.

15. Козлова, А. А. Экономическая безопасность как явление и понятие // Власть. 2009. № 1. С.14-17.

16. Криволевич, Е. А. К вопросу об экономической безопасности банковской системы страны // Нац. Интересы : приоритеты и безопасность. 2010. № 3. С. 55-62.

17. Лавренко, С. В. Финансовый контроль в системе обеспечения национальной экономической безопасности : институцииональный аспект / С. В. Лавренко, А. В. Романова // Финансы и кредит. 2010. № 26. C. $58-62$.

18. Максимов, Д. А. Рыночная устойчивость, экономическая безопасность и инновачионная стратегия предприятия в условиях трансформируемой экономики / Д. А. Максимов, М. А. Халиков // Менеджмент в России и за рубежом. 2009. № 2. С. 15-21.

19. Матвеев, Ю. А. Управление экономической безопасностью банка : обеспечение непрерывности деятельности / Ю. А. Матвеев // Банковское дело. 2007. № 7. С. 68-70.

20. Миляев, П. В. Экономическая безопасность коммерческого банка в системе национальной безопасности государства // Аудит и финансовый анализ. 2010. № 2.

21. Перекрестова, Л. В. Внешние и внутренние угрозы финансовой безопасности предприятия / Л. В. 


\section{Науменко C.M. IШЕвцОва О.Н.}

РАЗРАБОТКА ПОКАЗАТЕЛЕЙ УРОВНЯ ФИНАНСОВОЙ СОСТАВЛЯЮЩЕЙ ЭКОНОМИЧЕСКОЙ БЕЗОПАСНОСТИ БАНКА И СТРАТЕГИЙ ПО ЕЁ СОВЕРШЕНСТВОВАНИЮ

Перекрестова, Р. С. Папехин // Финансы и кредит. 2007. № 16. С. 68-75.

22. Плисеикий, Д. Экономическая безопасность : финансовые аспекты // Мировая экономика и международные отношения. 2010. № 5. С. 28-37.

23. Скляров, А. В. Мировой финансовый кризис и экономическая безопасность России : анализ, проблемы и перспективы. - М. : Экономика, 2010.

24. Сенчагов, В. К. Экономика, финансы, цеены : эволюция, трансформация, безопасность. - М. : Анкил, 2010.

25. Силов, Н. В. Об обеспечении экономической безопасности коммерческого банка // Деньги и кредит. 2009. № 11. C. 43-47.

26. Устинова, Л. Н. Экономическая безопасность предприятия : анализ, структура, модель // Национальные интересы : приоритетьл и безопасность. 2011. № 45. С. 67-71.

27. Фелюст, А. А. Роль финансовой безопасности в системе экономической безопасности Российской Федерации // Национальные интересы : приоритеты и безопасность. 2009. № 19. С. 67-69.

28. Черникова, Е. В. Финансовая безопасность как элемент системы национальной безопасности государства / Е.В. Черникова, О.С.Высоикая // Закон. 2010. № 7. С. 37-43.

29. Шубина, Т. В. Финансовые аспекты экономической безопасности компании // Микроэкономика. 2010. № 4. C. 52-160.

30. Официальный сайт Банка России. - URL : http://www.cbr.ru.

31. Офиичильный сайт OAO «Ставропольпромстройбанк». - URL : http//www.psbst.ru.

32. Развитие банковского сектора [Электронный ресурс]. - URL : http://www.banki.ru (портал о банкax).

33. Конщепция безопасности коммерческого банка [Электронный ресурс]. - URL : http://www.lawsportal.ru.

\section{References:}

1. Federal'nyj zakon o bankah i bankovskoj deyatel'nosti ot 02.12.1990 g. №395-1 FZ [red. ot 29.09.2011 g.].

2. Strategiya nacional'noj bezopasnosti Rossijskoj Federacii do $2020 \mathrm{~g}$. Utv. Ukazom prezidenta RF ot $12 \mathrm{ma-}$ ya 2009 g. № 537.

3. Berezina, M. P. Mezhbankovskie raschety : analiz praktiki / M.P. Berezina, YU.S. Krupnov. - M. : Den'gi i Kredit, 2010.

4. Bogomolov, V. A. Ekonomicheskaya bezopasnost' : ucheb. posobie dlya studentov vuzov, obuchayushchihsya po special'nostyam ekonomiki i upravleniya. - 2-e izd., pererab. i dop. - M. : YUNITI-DANA, 2009.

5. Bukato, V. I. Banki i bankovskie operacii v Rossii : uchebnik/V.I. Bukato, YU.I. L'vov. - M. : Finansy $i$ statistika, 2009.

6. Gamza, V. A. Tkachuk, I. B. Bezopasnost' kommercheskogo banka : organizacionno-pravovye $i$ kriminalisticheskie problemy : monografiya. - M. : Izd-l' SHumilova I.I., 2009.

7. Molchanov, A. V. Bankovskaya sistema Rossii : Nastol'naya kniga bankira ; red. kol. Gryaznova A.G. i dr. M. : DeKA, 2009.

8. Usoskin, V. M. Sovremennyj kommercheskij bank: upravlenie i operacii. 2010.

9. Okat'ev, K. V. Nauchno-prakticheskaya rabota na temu: "Ekonomiko-organizacionnye problemy obespecheniya bezopasnosti deyatel'nosti kommercheskih bankov i puti razvitiya i funkcionirovaniya sistem bezopasnosti»». - M., 2009.

10. Vasilenko, A. I. Voprosy ekonomicheskoj bezopasnosti Rossijskoj Federacii // V mire nauki. 2009 . № 3. S. 21-23.

11. Vlasenko, M. N. Informacionno-analiticheskoe obespechenie prinyatiya upravlencheskih reshenij znachimyj faktor povysheniya ekonomicheskoj bezopasnosti hozyajstvuyushchih subëktov v usloviyah razvitiya rynochnoj sistemy hozyajstvovaniya / M.N.Vlasenko, N.V. Unizhaev // Nac. Interesy : prioritety i bezopasnost'. 2010. № 33. S. 59-69.

12. Gordienko, D. V. Perspektivy povysheniya urovnya ekonomicheskoj bezopasnosti Rossii // Nac. Interesy : prioritety i bezopasnost'. 2010. № 15. S.33-4.

13. ZHilkina, YU. V. Podhody $k$ obespecheniyu ekonomicheskoj bezopasnosti // Nac. Interesy : prioritety i bezopasnost'. 2010. № 22. S. 62-70.

14. Kanaev, A. V. Strategicheskie napravleniya povysheniya ekonomicheskoj bezopasnosti nacional'noj bankovskoj sistemy [Tekst] / A. V. Kanaev // Finansy i kredit. 2008. № 20. S. 8-16.

15. Kozlova, A. A. Ekonomicheskaya bezopasnost' kak yavlenie i ponyatie // Vlast'. 2009. № 1. S.14-17.

16. Krivolevich, E. A. K voprosu ob ekonomicheskoj bezopasnosti bankovskoj sistemy strany // Nac. Interesy : prioritety i bezopasnost'. 2010. № 3. S. 55-62.

17. Lavrenko, S. V. Finansovyj kontrol'v sisteme obespecheniya nacional'noj ekonomicheskoj bezopasnosti : institucional'nyj aspekt / S. V. Lavrenko, A. V. Romanova // Finansy i kredit. 2010. № 26. S. 58-62.

18. Maksimov, D. A. Rynochnaya ustojchivost', ekonomicheskaya bezopasnost' i innovacionnaya strategiya predpriyatiya $v$ usloviyah transformiruemoj ekonomiki / D. A. Maksimov, M. A. Halikov // Menedzhment v Rossii $i$ za rubezhom. 2009. № 2. S. 15-21.

19. Matveev, YU. A. Upravlenie ekonomicheskoj bezopasnost'yu banka : obespechenie nepreryvnosti deyatel'nosti / YU. A. Matveev // Bankovskoe delo. 2007. № 7. S. 68-70.

20. Milyaev, P. V. Ekonomicheskaya bezopasnost' kommercheskogo banka v sisteme nacional'noj bezopasnosti gosudarstva // Audit i finansovyj analiz. 2010. № 2.

21. Perekrestova, L. V. Vneshnie $i$ vnutrennie ugrozy finansovoj bezopasnosti predpriyatiya / L. V. Perekrestova, R. S. Papekhin // Finansy i kredit. 2007. № 16. S. 68-75.

22. Pliseckij, D. Ekonomicheskaya bezopasnost' : finansovye aspekty // Mirovaya ekonomika i mezhdunarodnye 
otnosheniya. 2010. № 5. S. 28-37.

23. Sklyarov, A. V. Mirovoj finansovyj krizis i ekonomicheskaya bezopasnost' Rossii : analiz, problemy i perspektivy. - M. : Ekonomika, 2010.

24. Senchagov, V. K. Ekonomika, finansy, ceny : evolyuciya, transformaciya, bezopasnost'. - M. : Ankil, 2010.

25. Silov, N. V. Ob obespechenii ekonomicheskoj bezopasnosti kommercheskogo banka // Den'gi i kredit. 2009. № 11. S. 43-47.

26. Ustinova, L. N. Ekonomicheskaya bezopasnost' predpriyatiya : analiz, struktura, model' // Nacional'nye interesy : prioritety i bezopasnost'. 2011. № 45. S. 67-71.

27. Felyust, A. A. Rol' finansovoj bezopasnosti v sisteme ekonomicheskoj bezopasnosti Rossijskoj Federacii // Nacional'nye interesy : prioritety i bezopasnost'. 2009. № 19. S. 67-69.

28. CHernikova, E. V. Finansovaya bezopasnost' kak element sistemy nacional'noj bezopasnosti gosudarstva / E.V.CHernikova, O.S. Vysockaya // Zakon. 2010. № 7. S. 37-43.

29. SHubina, T. V. Finansovye aspekty ekonomicheskoj bezopasnosti kompanii // Mikroekonomika. 2010 . № 4. S. 52-160.

30. Oficial'nyj sajt Banka Rossii. - URL : http://www.cbr.ru.

31. Oficial'nyj sajt OAO «Stavropol'promstrojbank». - URL : http//www.psbst.ru.

32. Razvitie bankovskogo sektora [Elektronnyj resurs]. - URL : http://www.banki.ru (portal o bankah).

33. Koncepciya bezopasnosti kommercheskogo banka [Elektronnyj resurs]. - URL : http://www.laws-portal.ru. 